\title{
Impact of Global Dimming and Brightening on Estimating Solar Radiation from Air Temperature in China
}

\author{
$\mathrm{Na}$ Zhao $^{1, \mathrm{a}^{*}}$, Ji Liang ${ }^{1, \mathrm{~b}}$ and Yanping Chen ${ }^{2, \mathrm{c}}$ \\ ${ }^{1}$ School of Hydropower and Information Engineering, Huazhong University of Science and \\ Technology, Wuhan, China \\ ${ }^{2}$ Hydrology and Water Resources Survey Bureau of Shanxi Province, Taiyuan 030001,China \\ a na.zhao.2011@hust.edu.cn, ${ }^{b}$ larkwater1@163.com, ${ }^{c}$ cyp_sxswj@126.com
}

\begin{abstract}
Keywords: Solar energy, Global dimming and brightening, Global warming
Abstract. Estimation of solar radiation (SR) is important for energy plan, architectural design and solar energy systems. In China, it is necessary to explore estimating methods of SR because of the limited radiation measurement data. Based on meteorological data at 46 stations, temporal and spatial variations of annual SR and diurnal temperature range (DTR) were analyzed for different periods in this study. Results showed that average trends of DTR and SR were both dramatically declining for the global dimming period (1961-1990), but leveling off for the global brightening period (1991-2010), which indicated that DTR could be a reliable indicator of SR. Based on spatial analysis, SR trends were consistent with DTR trend at 43 stations during 1961 to 1990, while they were consistent for just 28 stations from 1991 to 2010 . Then empirical coefficient $\mathrm{Kr}$ in the equation of estimating SR from DTR in different time scale and different periods in each station was calculated to assess the influence of changing SR on $\mathrm{Kr}$. It can be permutated between monthly and annual Kr. However, there was significant but inconsistent variations in $\mathrm{Kr}$ for the period of 1991-2010 compared with 1961-1990, which suggested that global dimming and brightening had complicated effect on estimation of SR from DTR, with dramatic variability among different regions.
\end{abstract}

\section{Introduction}

Solar radiation is a primary energy source of the Earth's surface and many systems such as ecology and hydrology [1]. There is reliable evidence about that surface solar radiation (SR) has undergone significant decline during the 1960s-1980s but recovered increase trend since 1990s, which are known as "global dimming and brightening", both in China and other countries [2-5]. These long-term change of SR will affect solar energy resource assessment [6]. It is, however, important to note that, the number of meteorological stations recording SR data is very small compared to the number recording routine weather parameters, such as temperature [7], which is especially true in many parts of China [8, 9]. Therefore, estimation of SR from temperature is highly desirable.

Solar radiation reaching the ground is a key determinant of surface temperature [10]. Similar to previous findings in some other regions of the Earth, China experienced an obvious warming trend since 1960s [11]. However, daily maximum and minimum air temperature showed the different trends between the dimming period (from 1960s to 1980s) and the brightening period (since 1990s). Daily minimum air temperature significantly increased but daily maximum air temperature slightly decreased during 1960 s to 1980 s. Since 1990 s, daily maximum and minimum air temperature both showed increased trend [12]. Therefore, diurnal temperature range (DTR) decreased rapidly in the dimming period but the decline in DTR had halted in the brightening period. In the other words, DTR and SR changed at a similar pace.

Based on the relationship between DTR and SR, equations have been applied to estimate SR from DTR [13]. Models for estimating SR based on DTR include the algorithms suggested by Hargreaves \& Samani [14], Bristow \& Campbell [15] and Thornton \& Running [16]. Moreover, Makowski et al. [17] analyzed the relationship between DTR and SR in Europe between 1970 and 2005 on seasonal and decadal scale and provided strong evidence that DTR was a reliable representative of SR. Ye et al. [9] evaluated the impacts of changing SR on DTR and further gave the variation of empirical coefficient in 
the equation of estimating SR from DTR in China. However, the change of empirical coefficient should depict the different scenario in the geographical distribution.

This study attempts to assess whether DTR shows consistent changing trend with SR and how global dimming and brightening impacts estimation of SR from DTR, based on meteorological data (1961-2010) collected from 46 stations in China.

\section{Materials and Method}

Data. Meteorological data (monthly incoming global solar radiation, monthly average daily maximum and minimum air temperature in 46 stations from 1961 to 2010) were provided by the Meteorological Information Center of China Meteorological Administration (CMA) and available at the website of CMA Data Sharing Service System (http://cdc.cma.gov.cn/). Radiation and air temperature measurements recorded were validated by CMA using quality control procedures.

Method of Trend Analysis. Annual SR and DTR were evaluated with the nonparametric Mann-Kendall trend test which was commonly used in testing the randomness of hydro-climatic time-series. A $p$ value of $<0.05$ was used to indicate statistical significance.

Estimation of Solar Radiation. Hargreaves \& Samani [14] firstly suggested an equation used to estimate SR from air temperature.

$$
R_{s}=K r \times\left(T_{\max }-T_{\min }\right)^{0.5} \times R_{a} .
$$

where $R_{s}$ is solar radiation $\left(\mathrm{MJ} \mathrm{m}^{-2}\right.$ day $\left.^{-1}\right) ; \mathrm{T}_{\max }$ and $\mathrm{T}_{\min }$ are the daily maximum and minimum air temperatures $\left({ }^{\circ} \mathrm{C}\right)$ and $\left(\mathrm{T}_{\max }-\mathrm{T}_{\min }\right)$ means DTR; $\mathrm{Ra}$ is extraterrestrial radiation $\left(\mathrm{MJ} \mathrm{m}^{-2}\right.$ day $\left.{ }^{-1}\right)$ which is a function of latitude and day of the year; $\mathrm{Kr}$ is an empirical coefficient.

Originally, $\mathrm{Kr}$ was assigned as the value of 0.16 for interior regions and 0.19 for coastal regions, which meant it will vary in the different locations. Moreover, $\mathrm{Kr}$ was the function of year [9], which proved that it would vary due to the influenced of global dimming and brightening.

In this study, average monthly and annual $\mathrm{Kr}$ from 1961 to 2010 in each station was calculated to depict the spatial distribution of $\mathrm{Kr}$ in different time scale. Then average annual $\mathrm{Kr}$ in global dimming period (from 1961 to 1990) and brightening period (from 1991 to 2010) in each station were shown to assess the influence of changing solar radiation on $\mathrm{Kr}$.

\section{Results and Discussions}

Long-term Changes in Solar Radiation and Diurnal Temperature Range. The variations of annual SR and DTR from 1961 to 2010 averaged from the 46 stations are shown in Fig. 1. Obviously, trend of DTR was consistent with that of SR. They were both dramatically declining from 1960s to 1980s, but leveling off since 1990s.

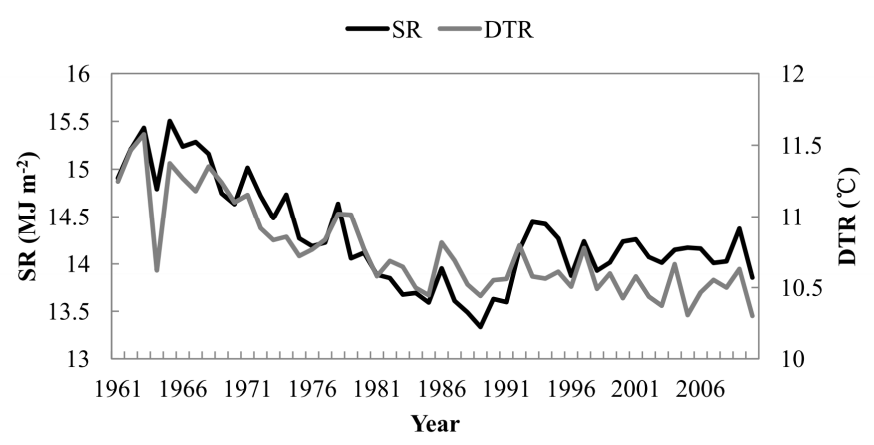

Fig. 1. Time series of solar radiation and diurnal temperature range from 1961 to 2010.

Statistically, trends of SR and DTR change are tested by the Mann Kendall method. Results showed that solar radiation decreased significantly $(Z=-6.24, P<0.001)$ from 1961 to 1990 at a rate of -25.64 MJ m-2 per year, and slightly decreased $(Z=-0.75, P>0.1)$ at a rate of $-2.82 \mathrm{MJ} \mathrm{m}^{-2}$ per year from 1991 to 2010. For the whole time series, negative trend in annual average SR was significant $(\mathrm{Z}=$ $-4.32, \mathrm{P}<0.001)$ at a rate of $-8.64 \mathrm{MJ} \mathrm{m}^{-2}$ per year. Therefore, global radiation change in this study 
does not fit well the pattern of "from dimming to brightening". It is also not consistent with abundant evidence of the transition in the SR trend in China in the past half century [9]. However, there are several studies which noted a sustained decline trend of SR across China in the 1950s-2000s. That may be because marginal brightening in the early 1990s cannot compensate for dramatic dimming in the whole period of 1961-2010 (Fig. 1).

Similarly, significantly negative tendency in DTR was observed $(Z=-5.25, P<0.001)$ from 1961 to 1990 at a rate of $-0.033^{\circ} \mathrm{C}$ per year. Slight decline $(Z=-1.91, P>0.05)$ was observed from 1991 to 2010 at a rate of $-0.011{ }^{\circ} \mathrm{C}$ per year, while the trend was insignificant. Negative trend in DTR was significant $(Z=-6.51, \mathrm{P}<0.001)$ at a rate of $-0.017{ }^{\circ} \mathrm{C}$ per year for the whole period. This observation is consistent with results of the early studies in China [9, 12], and the global scale [10].

In addition, Fig. 1 suggests that DTR and SR share similar decadal trends in China, both in the two different periods. It is worth noting that there is a significantly positive correlation $\left(\mathrm{R}^{2}=0.68, \mathrm{P}<\right.$ 0.001) between DTR and SR. Global dimming created a cooling effect which could masked the impact of greenhouse gases on global warming, especially on the maximum air temperature [10]. This mask was ceased or slowed down since 1990's when dimming gradually transformed into brightening, which was the reason of the decline of DTR leveled off. Therefore, decreasing trend in DTR is primarily affected by change of SR and DTR can be a reliable indicator of SR.

Spatial Trends in Solar Radiation and Diurnal Temperature Range. To compare the different variations of SR and DTR among 46 individual stations for the different periods, trends in annual SR and DTR for each station during the three periods (1961-2010, 1961-1990, 1991-2010) are shown in Fig. 2.

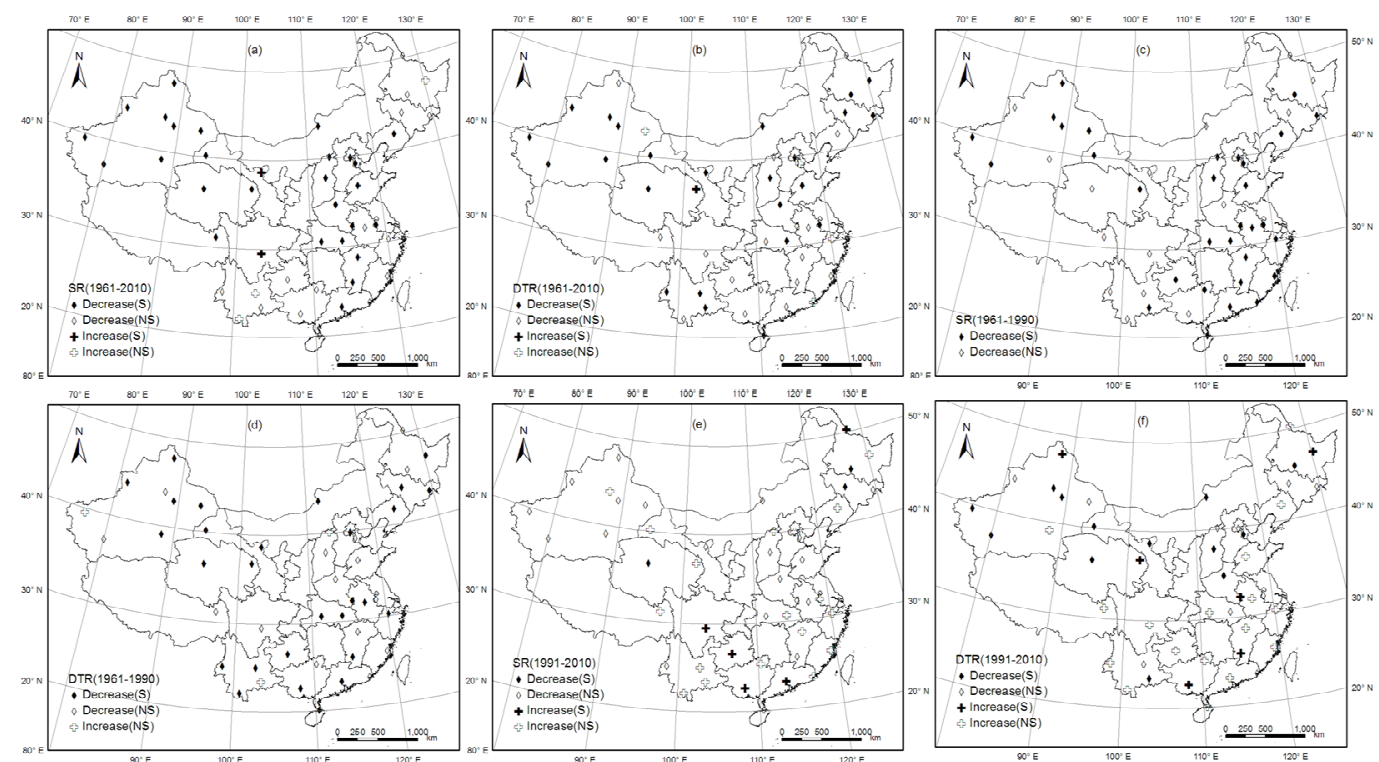

Fig. 2. Trends in annual solar radiation (SR) and diurnal temperature range (DTR) for the 46 stations in China for different periods (1961-2010, 1961-1990 and 1991-2010). S denotes significant and NS denotes non-significant.

In the whole period of 1961-2010, negative trends in SR were observed at 41 stations, and 27 of them were statistically significant (Fig. 2a). For the same period, DTR showed decreasing trends at 41 stations and 24 of them were statistically significant (Fig. 2b). It is worth noting that 36 stations show consistently decreasing trend in SR and DTR, but none of stations show consistently increasing trend. This indicates that DTR can be representative of SR in most of stations during 1961-2010. However, for other stations, it may need further studies in less time range.

During the period 1961 to 1990 , SR decreased at all 46 stations (significantly at 31 stations mainly located in the east and non-significantly in 15 stations of the west region) (Fig. 2c), which confirmed the influence of global dimming on China. Meanwhile, DTR decreased at 43 stations and increased insignificantly at other 3 stations (Fig. 2d). More consistent results between SR and DTR in this duration could verify the more reliable representative of DTR to SR. 
Moreover, from 1991 to 2010, SR decreased at 23 stations (significantly at 3 stations and non-significantly at 20 stations) and increased at other 23 stations (significantly at 5 station and non-significantly at 18 stations) (Fig. 2e). This reconfirmed that there was still a debate on China's brightening in the academic sphere [5]. At the same time, DTR also decreased at 23 stations (significantly at 13 stations and non-significantly at 10 stations) and increased at other 23 stations (significantly at 6 station and non-significantly at 17 stations) (Fig. 2f). It is necessary to note that SR trends were consistent with DTR trend at 43 stations (both were decreasing) during 1961 to 1990, while they were consistent for just 28 stations (both were decreasing for 14 and increasing for 14 stations) from 1991 to 2010. This suggests that the changes in DTR may be the effective indicator to SR in the period 1961 to 1990, but it could not well represent the changes in SR for the period of 1991 to 2010. Thus, evaluation of the impact of global dimming and brightening for the different periods (1961-1990 and 1991-2010) on estimation SR from DTR is needed.

Impact of global diming and brightening on estimating solar radiation from diurnal temperature range. Generally, the empirical coefficient $\mathrm{Kr}$ will keep relatively stable with time and space if SR and DTR show the similar trend. In this study, the inconsistency of trends in SR and DTR at many stations from 1991 to 2010 indicates that $\mathrm{Kr}$ may change in different periods and regions.

To depict the spatial variation of $\mathrm{Kr}$ in different time scale, average monthly and annual $\mathrm{Kr}$ from 1961 to 2010 in each station was calculated in Table 1. There was not dramatic difference between monthly $\mathrm{Kr}$ and annual $\mathrm{Kr}$. Monthly $\mathrm{Kr}$ was slightly higher than annual $\mathrm{Kr}$ for 30 stations, in which relative change was less than $4.5 \%$. This indicates that $\mathrm{Kr}$ coefficient calibrated with annual data can be successfully exchanged with those calibrated with monthly data to estimate the monthly value of SR. This exchangeability also implies that $\mathrm{Kr}$ in decadal time scale can be calculated from annual $\mathrm{Kr}$ data.

Table 1. The empirical coefficient $(\mathrm{Kr})$ of estimation solar radiation from diurnal temperature range in different time scales (monthly and annual) and periods (1961-1990 and 1991-2010).

\begin{tabular}{ccccc}
\hline Stations & monthly Kr & annual $\mathrm{Kr}$ & $\mathrm{Kr}(1961-1990)$ & $\mathrm{Kr}(1991-2010)$ \\
\hline Heihe & 0.163 & 0.156 & 0.156 & 0.156 \\
Jiamusi & 0.149 & 0.144 & 0.141 & 0.148 \\
Haerbin & 0.153 & 0.150 & 0.146 & 0.155 \\
Aletai & 0.172 & 0.174 & 0.176 & 0.171 \\
Yining & 0.152 & 0.154 & 0.155 & 0.152 \\
Wulumuqi & 0.163 & 0.169 & 0.168 & 0.170 \\
Tulufan & 0.158 & 0.159 & 0.159 & 0.158 \\
Kashi & 0.156 & 0.157 & 0.158 & 0.157 \\
Ruoqiang & 0.151 & 0.149 & 0.150 & 0.147 \\
Hetian & 0.163 & 0.160 & 0.159 & 0.162 \\
Hami & 0.168 & 0.166 & 0.170 & 0.161 \\
Dunhuang & 0.160 & 0.158 & 0.159 & 0.157 \\
Minqin & 0.156 & 0.153 & 0.148 & 0.160 \\
Geermu & 0.176 & 0.174 & 0.173 & 0.176 \\
Xining & 0.151 & 0.148 & 0.153 & 0.142 \\
Erlianhaote & 0.177 & 0.172 & 0.171 & 0.174 \\
Datong & 0.154 & 0.152 & 0.156 & 0.147 \\
Taiyuan & 0.140 & 0.138 & 0.144 & 0.130 \\
Changchun & 0.165 & 0.159 & 0.157 & 0.162 \\
Yanji & 0.139 & 0.135 & 0.132 & 0.139 \\
Shenyang & 0.152 & 0.150 & 0.152 & 0.146 \\
Beijing & 0.160 & 0.157 & 0.161 & 0.151 \\
Tianjin & 0.159 & 0.158 & 0.164 & 0.148
\end{tabular}




$\begin{array}{ccccc}\text { Jinan } & 0.154 & 0.153 & 0.156 & 0.149 \\ \text { Changdu } & 0.140 & 0.137 & 0.140 & 0.133 \\ \text { Emeishan } & 0.155 & 0.150 & 0.143 & 0.160 \\ \text { Tengchong } & 0.148 & 0.141 & 0.138 & 0.145 \\ \text { Kunming } & 0.146 & 0.142 & 0.138 & 0.150 \\ \text { Jinghong } & 0.140 & 0.136 & 0.135 & 0.138 \\ \text { Mengzi } & 0.153 & 0.151 & 0.148 & 0.155 \\ \text { Zhengzhou } & 0.138 & 0.138 & 0.139 & 0.137 \\ \text { Yichang } & 0.122 & 0.125 & 0.125 & 0.124 \\ \text { Wuhan } & 0.137 & 0.138 & 0.140 & 0.136 \\ \text { Guiyang } & 0.112 & 0.116 & 0.114 & 0.118 \\ \text { Guilin } & 0.127 & 0.128 & 0.128 & 0.130 \\ \text { Ganzhou } & 0.134 & 0.135 & 0.139 & 0.134 \\ \text { Gushi } & 0.147 & 0.145 & 0.151 & 0.143 \\ \text { Nanjing } & 0.140 & 0.138 & 0.140 & 0.139 \\ \text { Hefei } & 0.139 & 0.136 & 0.140 & 0.140 \\ \text { Hangzhou } & 0.133 & 0.134 & 0.134 & 0.136 \\ \text { Nanchang } & 0.146 & 0.144 & 0.152 & 0.145 \\ \text { Fuzhou } & 0.136 & 0.136 & 0.137 & 0.139 \\ \text { Guangzhou } & 0.131 & 0.127 & 0.132 & 0.127 \\ \text { Shantou } & 0.166 & 0.161 & 0.163 & 0.168 \\ \text { Nanning } & 0.135 & 0.137 & 0.140 & 0.133 \\ \text { Haikou } & 0.159 & 0.161 & 0.158 & 0.168\end{array}$

To assess the influence of changing SR on $\mathrm{Kr}$, average annual $\mathrm{Kr}$ in global dimming period (from 1961 to 1990) and brightening period (from 1991 to 2010) in each station were shown in Table 1. There was obvious variation in $\mathrm{Kr}$ for the period of 1991-2010 compared with 1961-1990. 25 stations showed negative trend in $\mathrm{Kr}$ but 21 stations showed opposite trend. The variation of $\mathrm{Kr}$ values ranged from -0.016 (relative change $-10.8 \%$ ) to 0.018 (relative change $11.9 \%$ ). There were 20 stations in which relative change of $\mathrm{Kr}$ was more than $4.5 \% . \mathrm{Kr}$ in 8 stations showed dramatic change more than 0.010 (relative change 6.5\%) and half of them showed negative trend. Overall, global dimming and brightening could take complicated but inconsistent effect on estimation of SR from DTR. Moreover, there was great variability of $\mathrm{Kr}$ value in space between the two periods.

Ye et al. [9] assessed the influence of solar dimming on estimating solar radiation from diurnal temperature range in China and found that $\mathrm{Kr}$ was a quadratic function of year. However, the spatial variability of this function was not under consideration. The contribution of this study compared to Ye et al. [9] is that $\mathrm{Kr}$ in different periods at each station is given to evaluate the comprehensive effect of global dimming and brightening on estimation of SR from DTR basted on temporal and spatial variations of $\mathrm{Kr}$. Actually, there were only 24 stations in all 46 stations in which $\mathrm{Kr}$ was function of year at the significant level in this study. Moreover, there were many different forms of functions for these 24 stations. That is to say, although $\mathrm{Kr}$ varies as quadratic function of year for averaging all stations due to the influence of global dimming, $\mathrm{Kr}$ function in Ye et al. [9] is not applicable to some specific regions in China.

Acknowledgements. This research is supported by the National Natural Science Foundation of China (No. 51409109). It is also funded by project 'Multi model study and parameter determination of flash floods in small watershed of Shanxi Province' and the Fundamental Research Funds for the Central Universities, HUST: 2014QN234. We acknowledge National Meteorological Information Centre of China for providing the meteorological data. 


\section{References}

[1] Tiwari G. N., Solar energy: fundamentals, design, modelling and applications, Alpha Science Int'1 Ltd., 2002.

[2] Wild M., Global dimming and brightening: A review, J. Geophys. Res. - Atmos. 114 (2009) D00D16.

[3] Wild M., Enlightening global dimming and brightening, B. Am. Meteorol. Soc. 93 (2012) 27-37.

[4] Wang Y. W., Yang Y. H., Zhao N., Liu C., Wang Q. X., The magnitude of the effect of air pollution on sunshine hours in China, J. Geophys. Res. 117 (2012) D00V14.

[5] Wang Y. W., Yang Y. H., China's dimming and brightening: evidence, causes and hydrological implications, Ann Geophys. 32 (2014) 41-55.

[6] Müller B., Wild M., Driesse A., Behrens K., Rethinking solar resource assessments in the context of global dimming and brightening, Solar Energy 99 (2014) 272-282.

[7] Thornton PE, Running SW., An improved algorithm for estimating incident daily solar radiation from measurements of temperature, humidity, and precipitation, Agric. Forest Meteorol. 93 (1999) 211-228.

[8] Chen RS, Ersi K, Yang JP, Validation of five global radiation models with measured daily data in China, Energy Convers. Manage. 45 (2004) 1759-1769.

[9] Ye J., Li F., Sun G., Guo A., Solar dimming and its impact on estimating solar radiation from diurnal temperature range in China, 1961-2007, Theor. Appl. Climatol. 101 (2010) 137-142.

[10] Wild M., Ohmura A., Makowski K., Impact of global dimming and brightening on global warming, Geophys. Res. Lett. 34 (2007) L04702

[11]Hu Z. Z., Yang S., Wu R., Long-term climate variations in China and global warming signals, J. Geophys. Res. 108(D19) (2003) 4614.

[12] Liu B, Xu M, Henderson M, Qi Y, Li Y, Taking China's temperature: daily range, warming trends, and regional variations, 1955-2000, J. Clim. 17 (2004) 4453-4462.

[13]Chen R., Kang E., Lu S., Yang J., Ji X., Zhang Z., Zhang J., New methods to estimate global radiation based on meteorological data in China, Energy Convers. Manage. 47 (2006) 2991-2998.

[14] Hargreaves GH, Samani ZA., Estimating potential evapotranspiration, J. Irrig. Drain Eng. ASCE 108(3) (1982) 225-230.

[15]Bristow KL, Campbell GS, On the relationship between incoming solar radiation and daily maximum and minimum temperature, Agric. Forest Meteorol. 31 (1984) 159-166.

[16] Thornton PE, Running SW, An improved algorithm for estimating incident daily solar radiation from measurements of temperature, humidity, and precipitation, Agric Forest Meteorol 93 (1999) 211-228.

[17] Makowski K, Jaeger EB, Chiacchio M, Wild M, Ewen T, Ohmura A., On the relationship between diurnal temperature range and surface solar radiation in Europe, J. Geophys. Res. 114 (2009) D00D07. 